\title{
DEVELOPING SKILLS
}

\section{Colin Hendrie}

Department of Psychology, University of Leeds, UK

\section{C.A.Hendrie@leeds.ac.uk}

\begin{abstract}
This paper describes the construction and use of ethograms: the sets of detailed descriptions of characteristic behaviours of the species under investigation. The importance of a good ethogram for ensuring consistency across observers is emphasised, which follows the standard scientific requirement for shared definitions of terms. The early stages are often informal, looking for patterns. Different techniques are used: e.g. scanning a number of individuals briefly observing each, following just one for some time. Part of the discipline is avoiding anthropomorphising, examples, with their hyperlinks, are given. Some of the techniques for developing behaviour categories, testing their reliability, and sampling them are descibed. The early stages, it is emphasised, can be lengthy and hard, but they pay dividends later in getting through to more useful, novel and objective descriptions and understandings of behaviour.
\end{abstract}

Keywords: Developing direct observation skills, ethogram, ethology.

The great advantage of the ethological approach is that applying Tinbergen's four questions (Tinbergen, 1963) gives a remarkable clarity to a wide range of issues, from molecular to societal. At the heart of all ethological analyses is the ethogram. Ethograms are sets of detailed descriptions of characteristic behaviour patterns of the species under investigation (Brown, 1975; Martin \& Bateson, 1995). There are guidelines that determine how ethograms are created; behavioural descriptions being unequivocal and behaviours to be recorded being mutually exclusive for example. There is also need for completeness of recording, which occasionally means that catchalls such as 'other' or 'out-of-sight' need to be included. The purpose of the ethogram is to ensure that 
methodology is consistent from one observer and one recording session to the next. It is also to make sure that what is recorded is clear and unequivocal and that anthropomorphism is avoided as far as is possible (see Lehner, 1996 section 4.2.2b). The aim of this short article is to illustrate the various stages of ethogram use and development.

In many instances ethograms may have already been developed in the researcher's own lab or already be available in print or on-line (see Ekman \& Friesen, 1978 and Appendix). Nonetheless, even when this is the case it is a useful exercise to go through the development process since repeated observation is required for both creating a new ethogram and learning how to use a pre-existing one.

Researchers new to the ethological approach should begin by observing behaviour in a relatively informal way, although formal analysis must eventually be used. The cooperative fishing strategy of the Laguna fisherman with the local dolphin population is a real-world illustration of how valuable this kind of informal ethological analysis can be (Pryor and Lindbergh, 1998). Film clips with an interesting content, such as the one shown in Figure 1, can be useful for training as observers remain attentive even after several viewings and repetition is required for patterns to emerge and relationships between behaviours to be seen. Experimenters can also try different sampling techniques when using filmed behaviour, comparing the result of exclusively following one interactant for the entirety of the observation period for example versus stopping the clip every 10 seconds, say, and noting what each animal/person is doing at that time point (see Lehner, 1996 section 8.3).
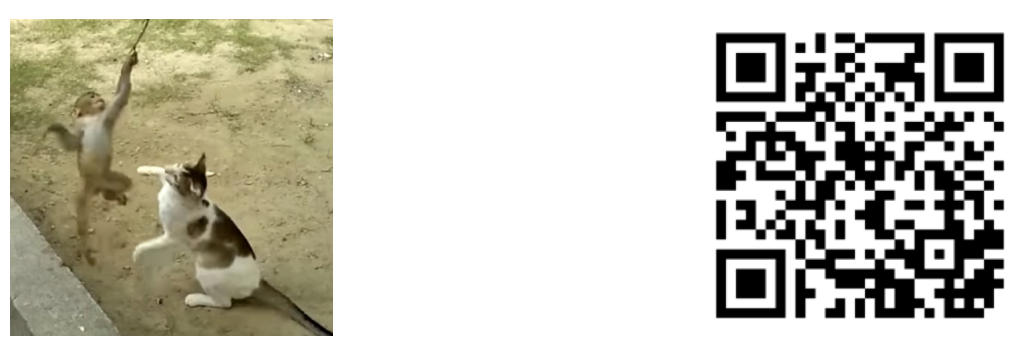

https://www.youtube.com/watch?v=YvF-ZTH28yl

Figure 1: Baby monkey and cat playing (Nikita Karki, 2014)

Great care must be taken with all observations to avoid anthropomorphism, the attributing of human emotions and cognitions on to animals that may not possess them (Topoff, 1987), as this almost invariably leads to false conclusions. The point about false attributions also applies when observing other cultures. Americans view a figure with a bowed head as being 'sad' for example, whilst Japanese see this as a posture indicating respect (Kleinsmith et al, 2006).

One of the most widely viewed examples of anthropomorphism is "Cat tries to revive dead friend" which has been seen by millions on YouTube and even reported on a national news channel. This film involves a street cat kneading the chest of another street cat that had recently been killed by a car. To YouTube viewers this was the cat's attempt at 
artificial resuscitation. In ethology however, it is critical to record the behaviours that are being expressed rather than the observer's views of what they think they are seeing. Kneading and pelvic thrusting form part of cat sexual behaviour (Stanton et al, 2015) and so the behaviour seen in this clip needs to be interpreted in that context.
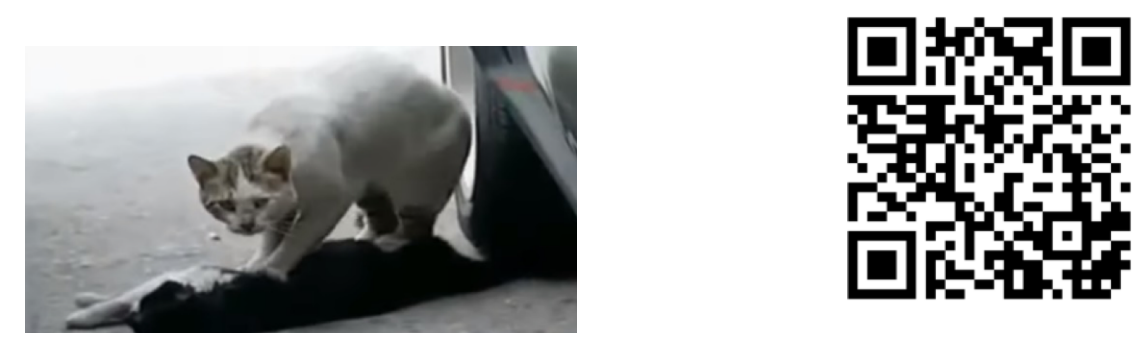

https://www.youtube.com/watch?v=zaP7STV1aFs

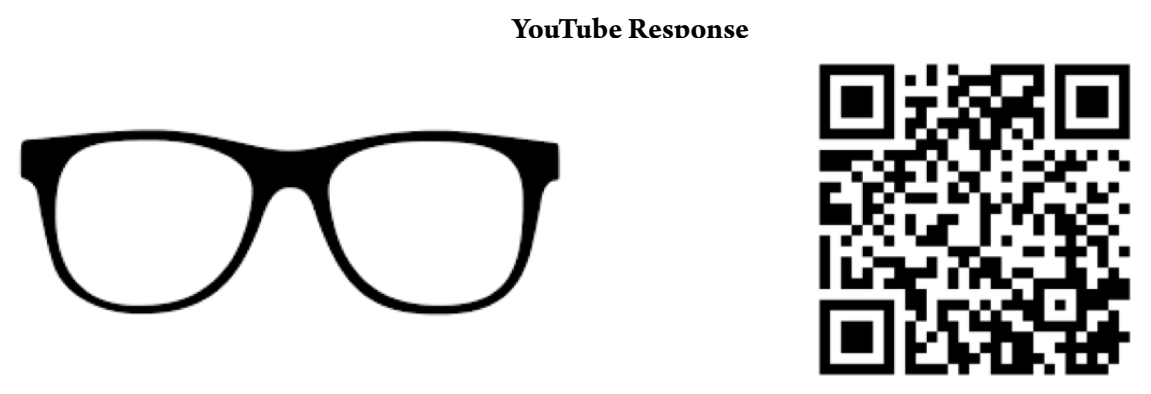

https://www.youtube.com/watch?v=EFZK9UYKhhw

Figure 2: "Cat tries to revive dead friend"

"Babies eating lemons for the first time" is very useful in a learning context, as the nature of the stimulus is clear and the behavioural reactions readily identifiable. The literature on the impact of taste on behaviour (e.g. Ganchrow et al, 1983; Berridge, 2000; Steiner et al, 2001; Weiland et al, 2010) also renders this a suitable exercise to be written up as a report, if that is also part of the training.

The process underlying the creation of the ethogram itself is best demonstrated by getting observers to view the clip 3-4 times and then asking them to report what behaviours they have observed. If this is done in a group setting it soon becomes apparent that most people are seeing the same things and this boosts the observer's confidence in the reliability of the method. The process of ethogram construction can then begin in earnest by producing definitions of the behaviours that have been observed and then assigning short codes to them so they can be quickly recorded (see Ekman \& Friesen, 1978 and Appendix). 

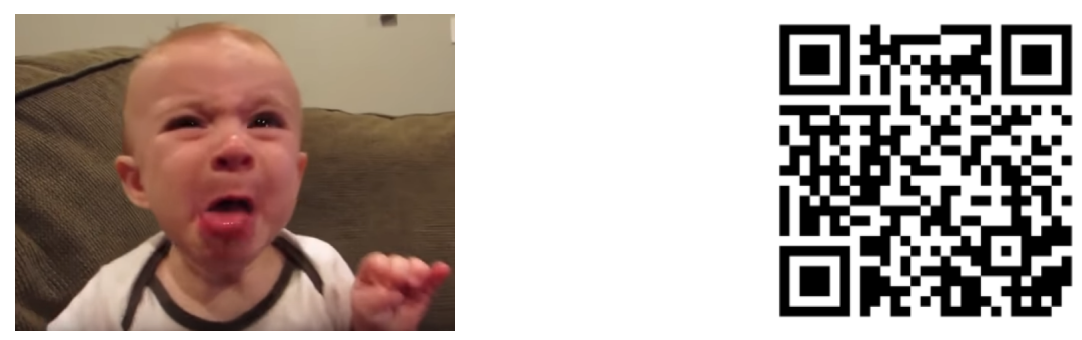

https://www.youtube.com/watch?v=z9jBfo0N3BI

Figure 3: "Babies eating lemons for the first time"

Discussions at this point can be directed towards what can and should be measured, i.e. whether this is frequency of behaviours, durations of behaviours, both frequencies and durations etc and how this should be sampled (Altmann, 1974). The concepts of behavioural sequences and sequence analysis can also be introduced (e.g. Slater, 1973; Kershenbaum, 2016) since it is clear that there is an order to what most babies do once having tasted the lemon. Observers also need to consider how they envisage recording behaviour, by using purpose written event recording software or apps (e.g. Hendrie \& Bennett, 1983), pen paper methods and so on (see Appendix).

Observers building an ethogram for "Babies sucking lemons for the first time" could compare the behavioural elements they have identified with those used by other workers. These include mouth gaping, headshaking, smiling, frowning, lip smacking, lip pursing, eye squinting, nose wrinkling etc (e.g. Rosenstein \& Oster, 1988; Steiner et al, 2001). There could at this point be some discussion about the utility of publishing ethograms without the detailed definitions of each behaviour needed to use them. The laughter of the parents/caregivers in the present example could also be considered an important behaviour to measure as this highlights the interactive nature of the babies' behaviour.

One of the final stages in observers developing their ethological skills is to ensure that the data being produced are reliable. To this end, filmed behaviour should be scored several times and the results of each analysis compared. The aim is to be able to produce a level of intra-observer reliability of at least $95 \%$. Where studies are to be scored by more than one observer then their inter-observer reliability should also be more than 95\% (see Lehner, 1996 section 8.5). Once these levels of skill have been attained there should also be regular checks to make sure that reliability is maintained.

In summary, developing the skills to construct ethograms and use them to record behaviour is labour intensive and involves repeatedly watching the same material to ensure that data are reliable and reproducible. The time spent in developing these skills is however well spent, as the ethological approach, and ethological analysis in particular, gives insights into behaviour that cannot be gained in any other way and once developed those skills are not forgotten. 


\section{REFERENCES}

Altmann, J. (1974). Observational study of behavior: sampling methods. Behaviour, 49(3), 227-266. DOI

Berridge, K. C. (2000). Measuring hedonic impact in animals and infants: microstructure of affective taste reactivity patterns. Neuroscience \& Biobehavioral Reviews, 24(2), 173-198. DOI

Brown, J.L. (1975). The evolution of behaviour. WW Norton, New York.

P. Ekman, W. Friesen (1978). The facial action coding system. Consulting Psychologists Press, Palo Alto, CA, USA

Ganchrow, J. R., Steiner, J. E., \& Daher, M. (1983). Neonatal facial expressions in response to different qualities and intensities of gustatory stimuli. Infant Behavior and Development, 6(4), 473-484. DOI

Hendrie, C.A. \& Bennett, S. (1983). A micro-computer technique for the detailed analysis of animal behaviour. Physiology \& Behavior, 30(2), 233-235. DOI

Kershenbaum, A., Blumstein, D. T., Roch, M. A., Akçay, Ç., Backus, G., Bee, M. A., ... \& Coen, M. (2016). Acoustic sequences in non-human animals: a tutorial review and prospectus. Biological Reviews, 91(1), 13-52. DOI

Kleinsmith, A., De Silva, P. R., \& Bianchi-Berthouze, N. (2006). Cross-cultural differences in recognizing affect from body posture. Interacting with Computers, 18(6), 1371-1389. DOI

Lehner, P. N. (1998). Handbook of ethological methods. Cambridge University Press.

Martin, P. and Bateson, P. 1995. Measuring Behaviour: An introductory guide. Cambridge University Press. DOI

Pryor, K., \& Lindbergh, J. (1990). A dolphin-human fishing cooperative in Brazil. Marine Mammal Science, 6(1), 77-82. DOI

Rosenstein, D., \& Oster, H. (1988). Differential facial responses to four basic tastes in newborns. Child development, 59(6), 1555-1568. DOI

Slater, P. J. B. (1973). Describing sequences of behavior. In: P. P. G. Bateson \& P. H. Klopfer (eds.). Perspectives in ethology (pp. 131-153). Springer, Boston, MA. DOI

Stanton, L. A., Sullivan, M. S., \& Fazio, J. M. (2015). A standardized ethogram for the felidae: A tool for behavioral researchers. Applied Animal Behaviour Science, 173, 3-16. DOI

Steiner, J. E., Glaser, D., Hawilo, M. E., \& Berridge, K. C. (2001). Comparative expression of hedonic impact: affective reactions to taste by human infants and other primates. Neuroscience \& Biobehavioral Reviews, 25(1), 53-74. DOI

Tinbergen, N. (1963). On aims and methods of ethology. Ethology, 20(4), 410-433. DOI

Topoff, H. R. (1987). The Natural History Reader in Animal Behavior. Columbia University Press.

Weiland, R., Ellgring, H., \& Macht, M. (2010). Gustofacial and olfactofacial responses in human adults. Chemical senses, 35(9), 841-853. DOI 


\section{APPENDIX - ON-LINE RESOURCES}

\section{Constructing an ethogram}

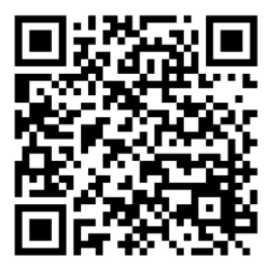

http://www.racerocks.com/racerock/jason/ethology/index.html

\section{Methods of sampling}

General discussion

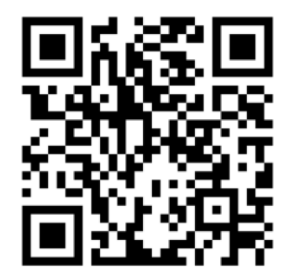

https://www.youtube.com/watch?v=KAYE-7L77Oc

\section{Example Ethograms}

Generic sample

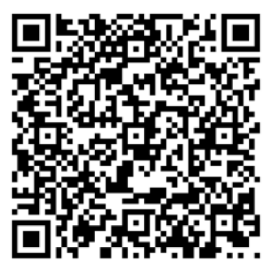

http://www.tolweb.org/onlinecontributors/ app;jsessionid=3E87A8FA157677E7473AAF2B7C784F $\underline{1 D ?}$

page=TeacherResourceViewSupportMaterial\&service =external\&sp=|3090\&sp=4
Focal sampling

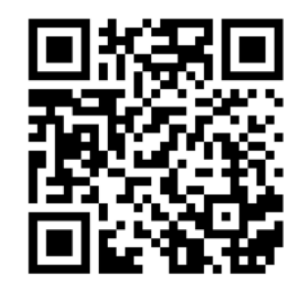

https://www.youtube.com/watch?v=ay-7LNMab40

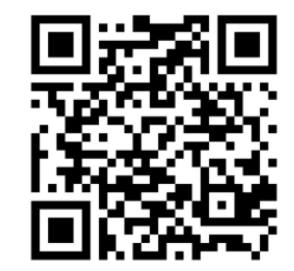

http://pin.primate.wisc.edu/callicam/ ethogram.html 


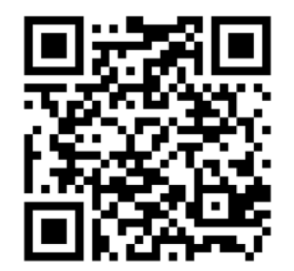

http://pin.primate.wisc.edu/callicam/ ethogram.html

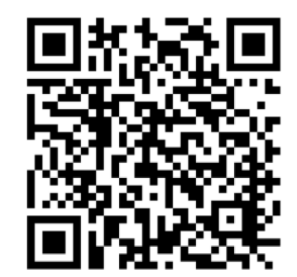

http://www.sciencedirect.com/science/article/pii/ $\underline{\text { S0149763498000360\#FIG4 }}$ 